\title{
Efficacy and safety of long-term transcutaneous electroacupuncture versus sham transcutaneous electroacupuncture for delayed gastric emptying after distal gastrectomy: study protocol for a randomized, patient-assessor blinded, controlled trial
}

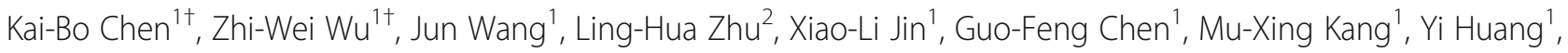
Hang Zhang ${ }^{1}$, Le-Le Lin ${ }^{1}$, Di-Ke Shi', Dan Wu' ${ }^{1}$, Jian-Feng Chen ${ }^{3}$, Jian Chen ${ }^{1}$ and Zhi-Qing Zhao ${ }^{3^{*}}$

\begin{abstract}
Background: Delayed gastric emptying (DGE) after distal gastrectomy impacts patients' nutritional status and quality of life. The current treatments of DGE seem unsatisfactory or need invasive interventions. It is unknown whether transcutaneous electroacupuncture (TEA) is effective in treating DGE.
\end{abstract}

Methods: A total of 90 eligible participants who underwent distal gastrectomy will be randomly allocated to either the TEA group ( $n=60)$ or the sham transcutaneous electroacupuncture (sham-TEA) group $(n=30)$. Each participant will receive TEA on the bilateral acupoints of Zusanli (ST36) and Neiguan (PC6) for 4 weeks. The primary outcomes will be the residual rates of radioactivity in the stomach by gastric scintigraphy and total response rates. The secondary outcomes will be endoscopic features, autonomic function, nutritional and psychological status, serum examination, and quality of life (QoL). The adverse events will also be reported. The patients will be followed up 1 year after the treatment.

Discussion: The findings of this randomized trial will provide high-quality evidence regarding the efficacy and safety of long-term TEA for treating DGE after distal gastrectomy.

Trial registration: Chinese Clinical Trial Registry ChiCTR2000033965. Registered on 20 June 2020

Keywords: Transcutaneous electroacupuncture, Delayed gastric emptying, Distal gastrectomy, Gastric cancer

\footnotetext{
*Correspondence: 1599051443@qq.com

${ }^{\dagger}$ Kai-Bo Chen and Zhi-Wei Wu contributed equally to this work.

${ }^{3}$ Department of General Surgery, Shang-Yu branch of SAHZU, School of Medicine, No. 517 Shi-Min Road, Shaoxing 312300, China

Full list of author information is available at the end of the article
}

C C The Author(s). 2022 Open Access This article is licensed under a Creative Commons Attribution 4.0 International License, which permits use, sharing, adaptation, distribution and reproduction in any medium or format, as long as you give appropriate credit to the original author(s) and the source, provide a link to the Creative Commons licence, and indicate if changes were made. The images or other third party material in this article are included in the article's Creative Commons licence, unless indicated otherwise in a credit line to the material. If material is not included in the article's Creative Commons licence and your intended use is not permitted by statutory regulation or exceeds the permitted use, you will need to obtain permission directly from the copyright holder. To view a copy of this licence, visit http://creativecommons.org/licenses/by/4.0/. The Creative Commons Public Domain Dedication waiver (http://creativecommons.org/publicdomain/zero/1.0/) applies to the data made available in this article, unless otherwise stated in a credit line to the data. 


\section{Background}

Gastric cancer is a common and lethal malignant disease worldwide. Although mortality has decreased substantially, approximately 0.5 million patients die of gastric cancer in China annually $[1,2]$. Early diagnosis of gastric cancer and radical gastrectomy improves the prognosis. However, patients have the possibility of rapid or delayed gastric emptying after distal gastrectomy, which impacts their nutritional status and quality of life (QoL) $[3,4]$. Specifically, 5-30\% of patients develop delayed gastric emptying (DGE) following gastrectomy [5-7]. Postsurgical gastroparesis syndrome (PGS) is also used for this complication [8]. Tomita et al. found that epigastric fullness occurred in $60 \%$ of patients who had received pylorus-preserving distal gastrectomy 5 years ago, gastric stasis in the remnant stomach occurred in $40 \%$ of these patients, and the gastric emptying function of a liquid and semisolid diet was decreased [9]. Kim et al. showed that over half of postoperative gastric cancer patients had DGE with frequently observed gastric stasis and reflux esophagitis [10]. Jung et al. reported that the incidence of food retention was 55.5\%, 31.9\%, and $20.9 \%$ at 3,12 , and 24 months, respectively, after distal gastrectomy for early gastric cancer patients [11].

Nutritional support, glycemic control, prokinetics, antiemetic medications, endoscopic self-expandable stent placement, and surgical intervention in severe cases are considered to be helpful for DGE patients [12]. Nevertheless, prokinetics lack clinical evidence with possible severe side effects, and secondary surgery is not a preferred choice for postoperative patients.

Acupuncture is widely applied for gastrointestinal motility disorders, and it has been proven effective in DGE in critically ill patients and postoperative gastroparesis syndrome [13]. A meta-analysis suggested that acupuncture with or without medication exhibited a significantly higher total effective rate than control acupuncture [14]. Transcutaneous electroacupuncture (TEA) is modified from traditional acupuncture, and it works on specific acupoints combined with a skin electrode patch instead of acupuncture [15]. In animal models, electroacupuncture (EA) can improve gastric motility, accelerate solid gastric emptying via the vagal mechanism, and ameliorate dyspepsia induced by chemotherapy [16]. A small number of clinical studies proved that TEA could significantly improve gastric emptying in dyspeptic patients [17]. Our previous randomized, controlled, single-center study demonstrated that TEA improved bowel movement and alleviated postoperative ileus after gastrectomy [18].

In this study, we will compare long-term TEA versus sham transcutaneous electroacupuncture (sham-TEA) for DGE after distal gastrectomy. To the best of our knowledge, this is the first randomized, patient-assessor blinded, controlled trial on this subject.

\section{Methods/design}

\section{Objectives and hypothesis}

This study aims to (1) assess the efficacy and safety of long-term TEA for treating DGE after distal gastrectomy and (2) evaluate postgastrectomy patients by endoscopic features, autonomic function, nutritional and psychological status, serum examination, quality of life, and TEA-related adverse events. We hypothesize that TEA can safely improve DGE after distal gastrectomy.

\section{Study design}

The trial will be conducted in the Second Affiliated Hospital of Zhejiang University, School of Medicine. This protocol was approved and monitored by the Medical Ethics Committees of the Second Affiliated Hospital of Zhejiang University, School of Medicine (approval number 2020-454), and Chinese Clinical Trial Registry (approval number ChiCTR2000033965) and will conform to the Declaration of Helsinki, STRICTA and SPIRIT guidelines (Fig. 1). The protocol of this study has been registered in the Chinese Clinical Trial Registry with the number ChiCTR2000033965. All eligible participants will be required to sign an informed consent form before allocation.

\section{Inclusion criteria}

All allocated patients met the following inclusion criteria: (1) 18-80 years old, (2) gastric cancer patients considered to have DGE (a half-life gastric emptying by gastric scintigraphy greater than $70 \mathrm{~min}$ ), (3) within 3-6 months after distal gastrectomy, (4) no gastrointestinal obstruction before surgery, and (5) TNM staging < IV, no distant metastasis.

\section{Exclusion criteria}

Patients who met any of the following criteria were excluded: (1) anastomotic stricture or afferent loop obstruction of the jejunum diagnosed by gastroesophageal radiography, (2) taking drugs such as prokinetics or antidepressant drugs a month prior to surgery or during the trial, (3) severe arrhythmia, (4) tumor recurs during the trial, (5) diabetes mellitus, or (6) mental and physiological illness.

\section{Dropout criteria}

Patients who choose to quit the study voluntarily or have poor compliance during the trial will be considered as having dropped out. Patients can discontinue the trial if a severe adverse effect occurs, and they can adjust the parameters of TEA slightly if the electric current makes them feel uncomfortable during the TEA procedure. 


\begin{tabular}{|c|c|c|c|c|c|c|c|}
\hline \multirow[b]{3}{*}{ TIMEPOINT } & \multicolumn{7}{|c|}{ STUDY PERIOD } \\
\hline & \multirow{2}{*}{$\begin{array}{c}\text { Enrolment } \\
0\end{array}$} & \multirow{2}{*}{$\frac{\text { Allocation }}{0}$} & \multicolumn{4}{|c|}{ Post-allocation } & \multirow{2}{*}{$\begin{array}{c}\text { Close-out } \\
\text { Follow-up } \\
(1 \text { year })\end{array}$} \\
\hline & & & Week 1 & Week 2 & Week 3 & Week 4 & \\
\hline \multicolumn{8}{|l|}{ ENROLMENT: } \\
\hline Eligibility screen & $\mathrm{X}$ & & & & & & \\
\hline Informed consent & $\mathrm{X}$ & & & & & & \\
\hline Allocation & & $\mathrm{X}$ & & & & & \\
\hline \multicolumn{8}{|l|}{ INTERVENTIONS: } \\
\hline \multicolumn{8}{|l|}{ TEA group } \\
\hline \multicolumn{8}{|l|}{ Sham-TEA group } \\
\hline \multicolumn{8}{|l|}{ ASSESSMENTS: } \\
\hline Baseline variables & $\mathrm{X}$ & $X$ & & & & & \\
\hline $\begin{array}{c}\text { Residual rates in the } \\
\text { stomach }\end{array}$ & & & $X$ & & & $X$ & $\mathrm{X}$ \\
\hline Total response rates & & & & & & $\mathrm{X}$ & \\
\hline Endoscopic features & & & $X$ & & & $\mathrm{X}$ & \\
\hline Autonomic function & & & $\mathrm{X}$ & & & $\mathrm{X}$ & \\
\hline Nutritional status & & & $X$ & $\mathrm{X}$ & $\mathrm{X}$ & $\mathrm{X}$ & $\mathrm{X}$ \\
\hline Serum test & & & $X$ & & & $\mathrm{X}$ & \\
\hline $\begin{array}{l}\text { Psychological } \\
\text { assessment }\end{array}$ & & & $\mathrm{X}$ & $\mathrm{X}$ & $X$ & $\mathrm{X}$ & \\
\hline Quality of life & & & $X$ & & & $\mathrm{X}$ & $\mathrm{X}$ \\
\hline Adverse events & & & & $X$ & $X$ & $X$ & \\
\hline $\begin{array}{c}\text { Data collection and } \\
\text { analysis }\end{array}$ & & & $\mathrm{X}$ & $\mathrm{X}$ & $\mathrm{X}$ & $X$ & $X$ \\
\hline
\end{tabular}

Fig. 1 SPIRIT schedule of enrollment, interventions, and assessments

\section{Recruitment}

A total of 90 gastric cancer patients who underwent distal gastrectomy at the gastrointestinal surgery department of the Second Affiliated Hospital of Zhejiang University, School of Medicine, will be included in this study (Fig. 2). Demographic information of the patients will be collected. 


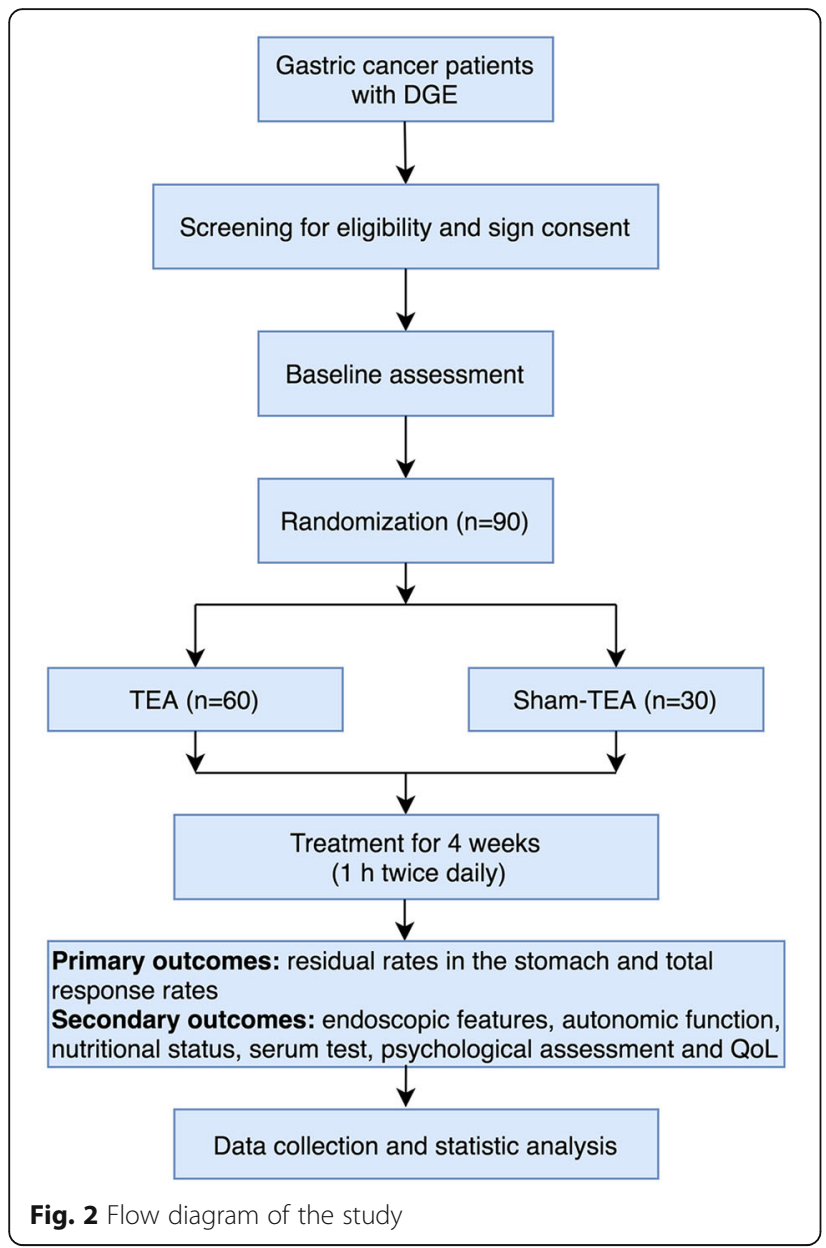

All patients will undergo laparoscopic exploration with peritoneal lavage cytology to exclude peritoneal metastasis. The patients will undergo distal gastrectomy for the primary tumor, D2 or D1+ lymph node dissection with truncal vagotomy by a single clinical team. Billroth-I, Billroth-II, or Roux-en-Y reconstruction will be conducted using staplers and suture reinforcement, and Braun anastomosis will not be performed for Billroth-II reconstruction. Patients who have a high risk of recurrence will receive adjuvant chemotherapy.

\section{Randomization}

All eligible patients will be randomly assigned to the TEA group or the sham-TEA group by an allocation ratio of 2:1, and the framework of the trial is assumed as superiority (Fig. 2). The randomization process will be achieved by opening sealed envelopes with computergenerated random numbers by the SPSS 22.0 software. The process will be implemented by a researcher who is not involved in the data collection or analysis.

\section{Interventions}

The researchers have been trained in the TEA technique in Pace Translation Medical Research Center, Ningbo, China, and they will teach the patients or their relatives how to implement TEA at home, with the help of a written or electronic user manual. Patients or their relatives can report adverse events by telephone or internet consultation.

\section{TEA group}

TEA will be performed with a skin electrode patch $(50 \times$ $50 \mathrm{~mm}$ ) accurately placed on bilateral acupoints of Zusanli (ST36) and Neiguan (PC6) based on the theory of traditional Chinese medicine and our previous study [19]. The TEA group will receive TEA $1 \mathrm{~h}$ twice daily for 4 weeks, and the parameters of TEA have been well designed for each acupoint: $0.1 \mathrm{~s}$ on, $0.4 \mathrm{~s}$ off, $100 \mathrm{~Hz}$, $0.25 \mathrm{~ms}, 2-6 \mathrm{~mA}$ at PC6, and $2 \mathrm{~s}$ on, $3 \mathrm{~s}$ off, $25 \mathrm{~Hz}, 0.5$ $\mathrm{ms}, 2-6 \mathrm{~mA}$ at ST36. The patients will feel mild electric current intermittently but not over the pain threshold, and they are free to perform a slight activity.

\section{Sham-TEA group}

The sham-TEA group will be performed in the same way except that the acupoints are $15 \mathrm{~cm}$ away from accurate acupoints. Ultimately, they will be evaluated for clinical outcomes after interventions for 4 weeks.

\section{Blinding}

The researchers who initially applied or taught the TEA or sham-TEA procedures did not participate in the statistical analysis. The patients and statisticians were blinded to the group assignments. If unblinding happens, the participants will be terminated from the trial immediately, and the data will be marked and not included in the final analysis. The researchers will record the reason in CRFs.

\section{Participant timeline}

Enrollment and allocation will be conducted before the study. TEA or sham-TEA intervention will be given twice daily from week 1 to week 4 . The patients' gastric emptying function, nutritional status, and quality of life (QoL) will be assessed 1 year after the treatment as a follow-up. The schedule of enrollment, allocation, postallocation, and close-out is shown in Fig. 1.

\section{Outcome measures}

\section{Primary outcome measures}

Gastric emptying function We will evaluate the gastric emptying function of these postoperative patients who visit outpatient clinics. Gastric scintigraphy will help us to evaluate the gastric emptying function and has the 
advantages of being noninvasive and painless. ${ }^{99 \mathrm{~m}} \mathrm{Tc}$ tin colloid will be mixed with a semisolid diet of $200 \mathrm{~g}$ of rice gruel with a boiled egg. Radioactive signs will be recorded from diet intake to $120 \mathrm{~min}$ afterward, and the residual rates of radioactivity in the stomach at 45,60 , $75,90,105$, and $120 \mathrm{~min}$ will be calculated by a half-life of $9 \mathrm{mTc}$. We will compare the recorded residual rates and the time to $50 \%$ residual rate between the two groups as the primary outcomes.

Total response rates We will compare the total response rates between the two groups. Meanwhile, we will perform a subgroup analysis by different operation types of Billroth-I, Billroth-II, or Roux-en-Y reconstruction. In fact, some researchers reported that Roux-en-Y reconstruction could destroy the natural small-bowel pacemaker [20-22]. Subgroup analysis of laparoscopic and open surgery will also be included in our results.

\section{Secondary outcome measures}

Endoscopic features DGE patients may have chronic inflammation of the upper digestive tract. Thus, endoscopy will be performed to determine reflux esophagitis, gastritis, and gastric stasis in the remnant stomach. We will compare the ratios of reflux esophagitis, gastritis, and gastric stasis between the two groups.

Autonomic function An electrocardiogram (ECG) will be performed on the first day and the last day of this trial, and it will assess the sympathetic and parasympathetic activities using the spectral analysis of heart rate variability (HRV). We will calculate the ratios of the low-frequency (LF) band and high-frequency (HF) band of the HRV signal, which can assess the autonomic function of the patients. A few studies have shown that electroacupuncture improves clinical outcomes via vagal activation [23-25]. ECG can assist us in revealing the mechanism of the effects of TEA on DGE.

Nutritional status The change in serum albumin and body mass index (BMI) will be recorded for nutritional status screening and evaluation. Additionally, the scored patient-generated subjective global assessment (PGSGA) (weight, food intake, symptoms, activities and function, disease state, metabolic demand, and nutritional physical examination) will be used to quickly identify malnutrition status, and patients will be scored as A (well-nourished), B (moderately malnourished or suspected malnutrition), and $\mathrm{C}$ (severely malnourished).

Psychological status Depression and anxiety symptoms will be assessed using the Hospital Anxiety Depression Scale (HADS). The HADS is a reliable self-rating scale questionnaire with seven items (scored from 0 to 3 ). A total HADS score over 10 indicates positive outcomes (moderate to severe symptoms).

Serum examination The likely mechanisms of TEA are activation of somatic and peripheral nerves, antiinflammatory effects, and functional preservation of the interstitial cells of Cajal [19]. Thus, blood will be taken for the analysis of serum norepinephrine (NE), tumor necrosis factor- $\alpha$ (TNF- $\alpha)$, interleukin-1 $\beta$ (IL-1 $\beta)$, interleukin-6 (IL-6), and glucose.

Quality of life (QoL) The QoL of the patients after distal gastrectomy will be evaluated using the Short Form 36 (SF-36) questionnaire, including physical functioning, role limitations due to physical problems, bodily pain, general health perception, vitality, social functioning, role limitations due to emotional problems, and mental health. Higher scores indicate better QoL.

\section{Safety and adverse effects}

The adverse events related to TEA or Sham-TEA will be monitored and reported by the patients themselves. It is possible to cause local events of TEA, such as skin bruising, itching, hematoma, pain, and muscular soreness, and systemic events, such as dizziness, arrhythmia, and gastrointestinal discomfort. Adverse effects will be recorded in the CRFs. The research team will provide costs of the treatment and corresponding financial compensation for these patients who suffer harm from trial participation according to the consent form.

\section{Sample size}

Based on a previous electroacupuncture study on gastric emptying function, the response rate is approximately $50-70 \%$ [26-30]; however, the data of sham electroacupuncture are insufficient. Thus, we assumed that the response rates of the TEA group and sham-TEA group were $50 \%$ and $20 \%$, respectively. Therefore, $\Delta$ is $30 \%$. We estimated the sample size using the following formula:

$$
n=\frac{2\left(\mu_{\alpha}+\mu_{\beta}\right)^{2} P(1-P)}{\Delta^{2}}
$$

A sample size of 66 patients will give us a power of $90 \%(\beta=0.1)$ with a two-sided significance level of 0.05 $(\alpha=0.05)$. To compensate for a $20 \%$ expulsion rate, a total of 90 patients will be required for the study. We will design a ratio of 2:1 (60 patients in the TEA group, 30 patients in the sham-TEA group) based on the response rates of the two groups. 


\section{Data management and monitoring}

The attending doctor who has performed the gastrectomy will be responsible for obtaining informed consent. Each participant will be required to sign an informed consent form and questionnaires and record personal information during the trial. The researchers will confirm the original data, collect all data on clinical outcomes very accurately, and store the data in the database safely. Clinical data will be carefully preserved using electronic and printed CRFs. To guarantee data quality, only outcome assessors will access the CRFs. Except for the researchers and the members of the ethics committee, people unrelated to the trial are not allowed to obtain access to CRFs. The personal information of the patients will not be disclosed in the public presentation. The data will only be used for this study. Biological specimens will be collected, stored, and analyzed in the current trial, and they are not intended for future use in ancillary studies. All data associated with the trial will be uploaded to the database of our hospital, and it will be monitored thoroughly by the Medical Ethics Committees.

\section{Statistical analysis}

Sensitivity analysis will be performed to determine the impact of incomplete records on the results. Intent-totreat analysis of the results will be performed if there is nonadherence or missing data. Only two data statisticians will have access to the final trial dataset, which will only contain coded data, and they will perform statistical analysis using the SPSS version 22.0 software. Student's $t$ test will be performed to assess the difference in the measurements (the residual rates of radioactivity in the stomach at 45, 60, 75, 90, 105, and $120 \mathrm{~min}$ ) between the TEA group and the sham-TEA group. Paired Student's $t$ test will be used to compare the differences in serum albumin, NE, TNF- $\alpha$, IL-1 $\beta$, IL-6, glucose, LF/HF (sympathovagal ratio), and QoL at baseline and 4 weeks after intervention in each group. The $\chi^{2}$ test will be used for categorical data such as the PG-SGA, HADS, and adverse events. Univariate and multivariate analyses with multiple linear regression will be used to identify independent predictors of outcome measures. The results will be aggregated as median values. $P$ values of $<0.05$ will be considered as statistically significant.

\section{Quality control}

To guarantee the quality of the study, all researchers were well trained in the TEA technique, and the patients or their relatives were taught to implement TEA at home, with the help of a written or electronic user manual. Pictures will be taken and uploaded to our database to check the proper acupoints and frequency of TEA each day. Plans to promote participant retention and complete follow-up are as follows: First, online video calls are available for consultation to resolve any technical issues of TEA implementation and to improve research adherence of the patients. Second, we will confirm the completion of TEA each week. Third, the expenses of round trips to the hospital and relevant examinations will be reimbursed to promote participant retention. Fourth, if the participants discontinue or deviate from the trial, we will collect as much data as possible for further analysis. Researchers will be fully apprised of the inclusion and exclusion criteria, and data will be documented in CRFs. A standard operating procedure will be consistently performed according to the study protocol. Drop-outs and their reasons will be recorded. The Medical Ethics Committees will audit the procedure of the trial, have access to these interim results and make the final decision to terminate the trial.

\section{Discussion}

DGE occurs after upper gastrointestinal tract surgery, including gastrectomy, pancreatic surgery, and esophagectomy [5, 31-33]. As the prognosis of gastric cancer patients improves, it turns out to be the main concern for patients with DGE after distal gastrectomy. DGE impacts the patients' nutritional status and QoL. Moreover, persistent DGE results in psychological diseases and even influences the prognosis of gastric cancer. However, the current treatments of DGE seem unsatisfactory or need invasive interventions, and prokinetics should be used cautiously due to their limited long-term efficacy and significant side effect. EA or TEA has been proven to be an effective treatment for improving gastrointestinal motility in either animal models or clinical cases [17, 23, 24, 34, 35]. Self-administrating TEA has been developed as a more convenient, patient-friendly treatment. It is promising for treating DGE after distal gastrectomy. The purpose of this trial was to evaluate the efficacy of TEA versus sham-TEA in improving gastric emptying function and the safety of TEA. The protocol of this trial is a well-designed, randomized, patientassessor blinded procedure, which will make the results convincing. Notably, we compared the TEA group versus the sham-TEA group rather than the medical treatment or control group, which ruled out a placebo effect.

Gastric scintigraphy is the gold standard method for the diagnosis of gastroparesis and DGE, but there is no uniform approach due to the differences in the composition, volume, and calories of the meal; the protocol of monitoring; and the analysis of data during the examination [36]. The definition of DGE after gastrectomy is not well addressed or studied. We defined DGE as a half-life of gastric emptying greater than 70 min according to previous studies $[9,37]$. Tougas et al. chose a lowfat meal consisting of ${ }^{99 \mathrm{~m}}$ Tc-labeled and scrambled eggs, two slices of bread, strawberry jam $(30 \mathrm{~g})$, and water 
$(120 \mathrm{ml})$; anterior and posterior images were taken at times of $1 \mathrm{~min}, 60 \mathrm{~min}, 120 \mathrm{~min}$, and $240 \mathrm{~min}$ in all patients, and the distribution of percent gastric residual retention at different time points was analyzed in 123 volunteers [38]. Similarly, Tomita et al. mixed ${ }^{99 \mathrm{~m}} \mathrm{Tc}$ tin colloids with a semisolid diet of $200 \mathrm{~g}$ of rice gruel with a raw egg. A gastric emptying curve was drawn based on the residual rate of radioactivity in the stomach [9]. Kim et al. used ${ }^{99 \mathrm{~m}} \mathrm{Tc}$ tin colloid-raidolabeled boiled eggs, and DGE was defined if a half-time of emptying was over $72 \mathrm{~min}$ [37]. In our trial, such a radioisotope method with endoscopy will be used to evaluate the gastric emptying function of these postgastrectomy patients. We will have ${ }^{99 \mathrm{~m}} \mathrm{Tc}$ tin colloid mixed with a semisolid diet of $200 \mathrm{~g}$ of rice gruel with a boiled egg, which is more in line with the appetites of Chinese people.

Gastric dysfunction after distal gastrectomy may be associated with damage to a gastric pacemaker (located at the junction between the fundus and the body of the greater curvature) and truncal vagotomy [39, 40]. Some studies reported that Roux-en-Y reconstruction could result in Roux-en-Y stasis syndrome due to the destruction of natural small-bowel pacemakers [20-22]. Kim et al. found that DGE was associated with laparoscopic operation and duration of the postoperative period [37]. Chong et al. revealed that gastric emptying within a week after distal gastrectomy was markedly slower in Billroth-I than in Billroth-II, while gastric emptying at 3-6 months showed no difference between the two groups [41]. Accordingly, it is necessary for subgroup analysis of different types of operations.

Several studies have indicated that TEA could increase vagal activity and suppress sympathetic activity [23, 25, 42, 43]. The LF and HF bands of ECG and the LF/HF ratio can well reflect vagosympathetic activities. Thus, we will assess the sympathetic and parasympathetic activities using ECG.

There are several limitations to our study. First, this trial will be conducted in a single center, so selection bias may exist. We suppose that confounding factors of surgical techniques and postoperative management will be eased if distal gastrectomy is performed by a single medical team. Second, TEA or sham-TEA will be implemented by the patients themselves at home, so the quality of manipulations cannot be guaranteed. Third, symptoms of upper abdominal fullness, early satiety, nausea, and vomiting will not be recorded because most DGE patients present with no specific symptoms $[11,37]$.

\section{Trial status}

Protocol version number V1, June 2020. The recruitment of this protocol is currently ongoing, and it is expected to be completed in December 2023.

\section{Abbreviations}

EA: Electroacupuncture; TEA: Transcutaneous electroacupuncture; shamTEA: Sham transcutaneous electroacupuncture; DGE: Delayed gastric emptying; PGS: Postsurgical gastroparesis syndrome; ECG: Electrocardiogram; HRV: Heart rate variability; LF: Low-frequency; HF: High-frequency; BMI: Body mass index; PG-SGA: Scored patient-generated subjective global assessment; NE: Norepinephrine; TNF-a: Tumor necrosis factor-a; IL-1 B: Interleukin-1 $\beta$; IL6: Interleukin-6; HADS: Hospital Anxiety Depression Scale; QoL: Quality of life; CRFs: Case report forms

\section{Acknowledgements}

The authors of this study protocol would like to sincerely thank Cong-Cong Yu and Jia-Ning Chen for their support.

\section{Authors' contributions}

$\mathrm{KBC}, \mathrm{WZW}, \mathrm{JC}$, and ZQZ designed the study protocol and drafted the manuscript. JW, LHZ, XLJ, GFC, MXK, YH, and $\mathrm{HZ}$ reviewed the study protocol and drafted the manuscript. LLL, DKS, DW, and JFC were responsible for the statistical design and analysis as trial statisticians. KBC and WZW are equal contributors. All authors carefully read and approved the final version of the manuscript.

\section{Funding}

This trial was financially supported by the Basic Public Welfare Research Project of Zhejiang Province (Grant No. LGD19H160004 and LGF21H030005), the Zhejiang Provincial Key Project of Research and Development Fund (Grant No. 2019C03043), the National Science and Technology Major Special Project for New Drug Development (Grant No. 2018ZX09201016), the Natural Science Foundation of Zhejiang Province (Grant No. LY19H160042), and the Clinical Research Fund of Zhejiang Medical Association (Grant No. 2018ZYCA118). The funders have no role in the design of the study and will not have any role during the execution, analyses, interpretation of the data, or decision to submit the results.

\section{Availability of data and materials}

There have been no baseline or pilot data in this study protocol to date. The data will be securely stored during the trial, and the final results will be published in a peer-reviewed journal.

\section{Declarations}

Ethics approval and consent to participate

This trial will be conducted according to the standards of the International Committee on Harmonization on Good Clinical Practice and the Declaration of Helsinki. This study protocol with written informed consent forms was peer-reviewed and approved by the Medical Ethics Committees of the Second Affiliated Hospital of Zhejiang University, School of Medicine (approval number 2020-454), and it was approved by the Chinese Clinical Trial Registry (approval number ChiCTR2000033965). Informed consent will be obtained from all participants.

\section{Consent for publication}

Written informed consent for publication will be obtained from all participants.

\section{Competing interests}

The authors declare that they have no competing interests.

\section{Author details}

'Department of Gastrointestinal Surgery, The Second Affiliated Hospital of Zhejiang University (SAHZU), School of Medicine, No.88 Jie-Fang Road, Hangzhou 310009, China. ${ }^{2}$ Department of Gastrointestinal Surgery, Sir Run Run Shaw Hospital, Zhejiang University, School of Medicine, No. 3 East Qing-Chun Road, Hangzhou 310020, China. ${ }^{3}$ Department of General Surgery, Shang-Yu branch of SAHZU, School of Medicine, No. 517 Shi-Min Road, Shaoxing 312300, China. 


\section{Received: 26 June 2021 Accepted: 15 February 2022}

Published online: 03 March 2022

\section{References}

1. Gao K, Wu J. National trend of gastric cancer mortality in China (2003-2015): a population-based study. Cancer Commun. 2019;39(1):5. https://doi.org/1 0.1186/s40880-019-0372-X

2. Li M, Wan X, Wang Y, Sun $Y$, Yang G, Wang L. Time trends of esophageal and gastric cancer mortality in China, 1991-2009: an age-period-cohort analysis. Sci Rep. 2017;7(1):6797. https://doi.org/10.1038/s41598-017-07071-5.

3. Karanicolas PJ, Graham D, Gonen M, et al. Quality of life after gastrectomy for adenocarcinoma: a prospective cohort study. Ann Surg. 2013;257(6): 1039-46. https://doi.org/10.1097/SLA.0b013e31828c4a19.

4. Davis $\mathrm{J}$, Ripley RT. Postgastrectomy syndromes and nutritional considerations following gastric surgery. Surgical Clinics of North America. 2017;97(2):277-93. https://doi.org/10.1016/j.suc.2016.11.005.

5. Cohen AM, Ottinger LW. Delayed gastric emptying following gastrectomy. Annals of Surgery. 1976;184(6):689-96. https://doi.org/10.1097/00000658-1 97612000-00005

6. Jordan GL, Walker LL. Severe problems with gastric emptying after gastric surgery. Annals of Surgery. 1973;177(6):660-8. https://doi.org/10.1097/ 00000658-197306000-00004.

7. BarNatan M, Larson GM, Stephens G, et al. Delayed gastric emptying after gastric surgery. Am J Surg. 1996;172(1):24-8. https://doi.org/10.1016/S0002 9610(96)00048-7.

8. Meng H, Zhou D, Jiang X, Ding W, Lu L. Incidence and risk factors for postsurgical gastroparesis syndrome after laparoscopic and open radical gastrectomy. World J Surg Oncol. 2013;11(1):144-4. https://doi.org/10.11 86/1477-7819-11-144.

9. Tomita R, Fujisaki S, Tanjoh K. Pathophysiological studies on the relationship between postgastrectomy syndrome and gastric emptying function at 5 years after pylorus-preserving distal gastrectomy for early gastric cancer. World J Surg. 2003;27(6):725-33. https://doi.org/10.1007/s00268-003-6906-y.

10. Kim DH, Yun HY, Song YJ, Ryu DH, Han HS, Han JH, et al. Clinical features of gastric emptying after distal gastrectomy. Ann Surg Treat Res. 2017;93(6): 310-5. https://doi.org/10.4174/astr.2017.93.6.310.

11. Jung $\mathrm{HJ}$, Lee JH, Ryu KW, Lee JY, Kim CG, Choi IJ, et al. The influence of reconstruction methods on food retention phenomenon in the remnant stomach after a subtotal gastrectomy. J Surg Oncol. 2008;98(1):11-4. https://doi.org/10.1002/jso.21076.

12. Kim SH, Keum B, Choi HS, Kim ES, Seo YS, Jeen YT, et al. Self-expandable metal stents in patients with postoperative delayed gastric emptying after distal gastrectomy. World J Gastroenterol. 2018;24(40):4578-85. https://doi. org/10.3748/wjg.v24.140.4578.

13. Pfab F, Winhard M, Nowak-Machen M, Napadow V., Irnich D., Pawlik M., Bein T., Hansen E. Acupuncture in critically ill patients improves delayed gastric emptying: a randomized controlled trial. Anesth Analg 2011; 112(1):150-155, 1, DOI: https://doi.org/10.1213/ANE.0b013e3181fdfac8.

14. Cheong KB, Zhang JP, Huang Y. The effectiveness of acupuncture in postoperative gastroparesis syndrome--a systematic review and metaanalysis. Complement Ther Med. 2014;22(4):767-86. https://doi.org/10.1016/ j.ctim.2014.05.002.

15. Chen JDZ, Ni M, Yin J. Electroacupuncture treatments for gut motility disorders. Neurogastroenterol Motil. 2018;30(7):e13393. https://doi.org/1 $0.1111 / \mathrm{nmo} .13393$

16. Liu Y, Zhang S, Ye F, Yin J, Li S, Chen JDZ. Ameliorating effects and mechanisms of chronic electroacupuncture at ST36 in a rodent model of dyspepsia induced by cisplatin. Neurogastroenterol Motil. 2019;31(1):e13474 https://doi.org/10.1111/nmo.13474.

17. Ji T, Li X, Lin L, Jiang L, Wang M, Zhou X, et al. An alternative to current therapies of functional dyspepsia: self-administrated transcutaneous electroacupuncture improves dyspeptic symptoms. Evid Based Complement Alternat Med. 2014;2014:832523-7. https://doi.org/10.1155/2014/832523.

18. Chen KB, Lu YQ, Chen JD, Shi DK, Huang ZH, Zheng YX, et al. Transcutaneous electroacupuncture alleviates postoperative ileus after gastrectomy: a randomized clinical trial. World J Gastrointest Surg. 2018; 10(2):13-20. https://doi.org/10.4240/wjgs.v10.i2.13.

19. Chen KB, Huang $Y$, Jin $X L$, Chen GF. Electroacupuncture or transcutaneous electroacupuncture for postoperative ileus after abdominal surgery: a systematic review and meta-analysis. Int J Surg. 2019;70:93-101. https://doi.org/10.1016/j.ijsu.2019.08.034.
20. Kinoshita T, Honda M, Matsuki A, Enomoto N, Aizawa M, Nunobe S, et al. Billroth-I vs Roux-en-Y after distal gastrectomy: a comparison of long-term nutritional status and survival rates from a large-scale multicenter cohort study. Annals of Gastroenterological Surgery. 2020;4(2):142-50. https://doi. org/10.1002/ags3.12309.

21. Sulav $P, X i n ~ S, A h m a d H K$, et al. An analysis of possible risk factors contributing to delayed gastric emptying after distal gastrectomy for gastric cancer. J Gastrointestinal Digest Syst. 2017;07(02).

22. Hirao M, Fujitani K Fau - Tsujinaka T, Tsujinaka T. Delayed gastric emptying after distal gastrectomy for gastric cancer. Hepatogastroenterology. 2005; $52(61)$.

23. Zhang B, Xu F, Hu P, Zhang M, Tong K, Ma G, et al. Needleless transcutaneous electrical acustimulation: a pilot study evaluating improvement in post-operative recovery. Am J Gastroenterols. 2018;113(7): 1026-35. https://doi.org/10.1038/s41395-018-0156-y.

24. Song J, Yin J, Sallam HS, Bai T, Chen Y, Chen JD. Electroacupuncture improves burn-induced impairment in gastric motility mediated via the vagal mechanism in rats. Neurogastroenterol Motil. 2013;25(10):807-e635. https://doi.org/10.1111/nmo.12183.

25. Huang Z, Zhang N, Xu F, Yin J, Dai N, Chen JDZ. Ameliorating effect of transcutaneous electroacupuncture on impaired gastric accommodation induced by cold meal in healthy subjects. J Gastroenterol Hepatol. 2016; 31(3):561-6. https://doi.org/10.1111/jgh.13168.

26. Iwa M, Nakade Y, Pappas TN, Takahashi T. Electroacupuncture improves restraint stress-induced delay of gastric emptying via central glutaminergic pathways in conscious rats. Neuroscience Letters. 2006;399(1-2):6-10. https://doi.org/10.1016/j.neulet.2005.11.069.

27. Liu Y, Zhang SJ, Ye F, et al. Ameliorating effects and mechanisms of chronic electroacupuncture at ST36 in a rodent model of dyspepsia induced by cisplatin. Neurogastroenterol Motility. 2019;31(1)

28. Yin JY, Chen JDZ. Electroacupuncture improves rectal distension-induced delay in solid gastric emptying in dogs. American Journal of PhysiologyRegulatory Integrative and Comparative Physiology. 2011;301(2):R465-72. https://doi.org/10.1152/ajpregu.00271.2010.

29. Ji T, Li XL, Lin L, Jiang L, Wang M, Zhou X, et al. An alternative to current therapies of functional dyspepsia: self-administrated transcutaneous electroacupuncture improves dyspeptic symptoms. Evid Based Complement Alternat Med. 2014;2014:1-7. https://doi.org/10.1155/2014/832523.

30. Xu SP, Hou XH, Zha H, Gao Z, Zhang Y, Chen JDZ. Electroacupuncture accelerates solid gastric emptying and improves dyspeptic symptoms in patients with functional dyspepsia. Dig Dis Sci. 2006;51(12):2154-9. https://doi.org/10.1007/s10620-006-9412-x

31. Noorani A, Rangelova E, Del Chiaro M, et al. Delayed gastric emptying after pancreatic surgery: analysis of factors determinant for the short-term outcome. Front Surg. 2016;3:6. https://doi.org/10.3389/fsurg.2016.00025.

32. Lee HS, Kim MS, Lee JM, Kim SK, Kang KW, Zo Jl. Intrathoracic gastric emptying of solid food after esophagectomy for esophageal cancer. Ann Thorac Surg. 2005;80(2):443-8. https://doi.org/10.1016/j.athoracsur.2005.02.049.

33. Li B, Zhang J-H, Wang C, Song TN, Wang ZQ, Gou YJ, et al. Delayed gastric emptying after esophagectomy for malignancy. J Laparoendosc Adv Surg Tech. 2014;24(5):306-11. https://doi.org/10.1089/lap.2013.0416.

34. Yin J, Chen JD. Electroacupuncture improves rectal distension-induced delay in solid gastric emptying in dogs. Am J Physiol Regul Integr Comp Physiol. 2011;301(2):R465-72. https://doi.org/10.1152/ajpregu.00271.2010.

35. Xu S, Hou X, Zha H, Gao Z, Zhang Y, Chen JDZ. Electroacupuncture accelerates solid gastric emptying and improves dyspeptic symptoms in patients with functional dyspepsia. Dig Dis Sci. 2006;51(12):2154-9. https://doi.org/10.1007/s10620-006-9412-x.

36. McCallum RW, George SJ. Gastric dysmotility and gastroparesis. Current Treatment Options in Gastroenterology. 2001; 4(2):179-191, DOl: https://doi. org/10.1007/s11938-001-0030-6.

37. Kim DH, Yun HY, Song Y-J, Ryu DH, Han HS, Han JH, et al. Clinical features of gastric emptying after distal gastrectomy. Ann Surg Treat Res. 2017;93(6): 310-5. https://doi.org/10.4174/astr.2017.93.6.310.

38. Tougas G, Eaker EY, Abell TL, Abrahamsson H, Boivin M, Chen J, et al. Assessment of gastric emptying using a low fat meal: establishment of international control values. Am J Gastroenterol. 2000;95(6):1456-62. https://doi.org/10.1111/j.1572-0241.2000.02076.x.

39. Hasler WL. Gastroparesis: pathogenesis, diagnosis and management. Nat Rev Gastroenterol Hepatol. 2011:8(8):438-53. https:/doi.org/10.1038/nrga stro.2011.116. 
40. Matsumoto S, Wakatsuki K, Migita K, Ito M, Nakade H, Kunishige T, et al. Predictive factors for delayed gastric emptying after distal gastrectomy with Roux-en-Y reconstruction. Am Surg. 2018;84(6):1086-90. https://doi.org/1 $0.1177 / 000313481808400670$

41. Chong A, Ha JM, Kim S. Gastric emptying scan after distal subtotal gastrectomy: differences between Billroth I and II and predicting the presence of food residue at endoscopy. Int I Clin Exp Med. 2015;8(11): 20769-77.

42. Song J, Yin JY, Chen JD. Needleless transcutaneous electroacupuncture improves rectal distension-induced impairment in intestinal motility and slow waves via vagal mechanisms in dogs. Int J Clin Exp Med. 2015;8(3): 4635-46.

43. Hu YD, Zhang B, Shi XD, et al. Ameliorating effects and autonomic mechanisms of transcutaneous electrical acustimulation in patients with gastroesophageal reflux disease. Neuromodulation. 8.

\section{Publisher's Note}

Springer Nature remains neutral with regard to jurisdictional claims in published maps and institutional affiliations.

Ready to submit your research? Choose BMC and benefit from:

- fast, convenient online submission

- thorough peer review by experienced researchers in your field

- rapid publication on acceptance

- support for research data, including large and complex data types

- gold Open Access which fosters wider collaboration and increased citations

- maximum visibility for your research: over $100 \mathrm{M}$ website views per year

At BMC, research is always in progress.

Learn more biomedcentral.com/submissions 